\title{
The effect of high temperature on tensile strength of sandstone
}

\author{
Chao Lü · Qiang Sun ${ }^{(凶)} \cdot$ Weiqiang Zhang · Jishi Geng · Yueming Qi Liangliang Lu \\ School of Resources and Geosciences, China University of Mining and Technology, Xuzhou, \\ Jiangsu Province 221116, P.R.China
}

Corresponding author: Tel: +86-516-83591015; E-mail address: 2278528194@qq.com ; sunqiang04@126.com.

\begin{abstract}
Heating at high temperature will make the tensile strength of sandstone change due to the loss of water and minerals and the effect of thermal stress. In this paper, the sandstone samples are heated from room temperature to $900^{\circ} \mathrm{C}$ in a high temperature furnace and then are subjected to Brazilian test with a computer-controlled hydraulic universal testing machine. The longitudinal wave velocity, total energy absorbed per unit thickness of disc and mass loss rate are comprehensively investigated. The results show that the tensile strength changes in the following four phases: from room temperature to $300^{\circ} \mathrm{C}, 300-600^{\circ} \mathrm{C}, 600-800^{\circ} \mathrm{C}$ and $800-900^{\circ} \mathrm{C}$, among which the tensile strength decreases rapidly in the second $\left(300-600^{\circ} \mathrm{C}\right)$ and fourth phases $\left(800-900^{\circ} \mathrm{C}\right)$ owing to the thermal stress that the most conspicuous effect is the expansion of quartz. The changing trends of tensile strength, longitudinal wave velocity and total energy absorbed per unit thickness of disc along with the temperature are similar.
\end{abstract}

Keywords: sandstone; tensile strength; heating at high temperature; thermal stress.

\section{Introduction}

Effect of temperature on the physical and mechanical properties of rock is an important research topic in the field of rock mechanics [1]. In many cases, the rock mass may be affected by high temperature, underground coal gasification [2], underground development of deep mine oil and gas 
storage cavern [3], burial of highly radioactive nuclear waste [4], development of geothermal resources [5-6] and fire in exploitation of underground rock [7-9]. The physical and mechanical properties of rock will change obviously after high temperature, such as the decrease of strength, elastic modulus and longitudinal wave velocity [10-11]. Those changes may cause irreparable loss if there are no good remedial measures. Therefore, the problem of rock engineering in high temperature environment has become the new development of rock mechanics [4].

Many studies have got certain achievements focusing on physical and mechanical properties of rock under high temperature [1-20]. The tensile strength is a key parameter for determining the rock's load bearing capacity, deformation, damage, fracturing and crushing, etc., therefore it is used to analyze the stability and serviceability of rock structures [21]. There are many test methods to determine the tensile strength such as Brazilian tensile strength test [22], flatten Brazilian disc [23], semi-circular bending test [24] and ring test [25]. The Brazilian tensile strength test is widely applied to rock engineering because it is easy to conduct, specimens are easy to prepare and uniaxial compression test machines are quite common [21]. Zhao et al. [8] studied the changing trends of density, longitudinal wave velocity and tensile strength of grit stone after high temperature. Su et al. [16] investigated the effect of temperature and sample size on the tensile strength by carrying out the Brazilian tensile strength test at five temperature levels ranging from $20^{\circ} \mathrm{C}$ to $800^{\circ} \mathrm{C}$. Dan et al. [26] carried out a series of Brazilian tests on Mosel slate and simulated the deformation process and failure behavior of the foliated rock samples. Liu et al. [27] used an electro-hydraulic and servo-controlled material testing machine and a split Hopkinson pressure bar to conduct static and dynamic compression and splitting tensile tests in order to make a full study on the static and dynamic mechanical properties of high-temperature-treated granite.

Therefore, the study on tensile strength of sandstone is of great significance in a wide range. 
Based on the above, by taking the tensile strength as the clue, we analyzed the variations of longitudinal wave velocity, mass loss rate and total energy absorbed per unit thickness of disc with temperature in this paper. Thermal stress at different temperatures was also discussed. This study is expected to provide a scientific basis of high temperature rock mechanics for the prediction and evaluation of the stability and safety of rock mass after high temperature.

\section{Experiment preparations and test methods}

We obtained the tested samples of sandstone from Linyi, Shandong province. The average density of sandstone samples is about $2.41 \mathrm{~g} / \mathrm{cm}^{3}$ and the natural content of water is about $0.07 \%$. The sandstone samples mainly consist of quartz, dolomite/ankerite, feldspar and kaolinite. The procedures of this experiment are shown in Fig.1. First of all, we cut samples into $\Phi 50 \times 30 \mathrm{~mm}$ disc specimens and numbered in sequence, and then heated them to the specified temperature $\left(25^{\circ} \mathrm{C} 、 50\right.$ ${ }^{\circ} \mathrm{C} 、 150{ }^{\circ} \mathrm{C} 、 200{ }^{\circ} \mathrm{C} 、 250{ }^{\circ} \mathrm{C} 、 300{ }^{\circ} \mathrm{C} 、 350{ }^{\circ} \mathrm{C} 、 400{ }^{\circ} \mathrm{C} 、 450{ }^{\circ} \mathrm{C} 、 500{ }^{\circ} \mathrm{C} 、 550{ }^{\circ} \mathrm{C} 、 600{ }^{\circ} \mathrm{C} 、$ $650{ }^{\circ} \mathrm{C} 、 700{ }^{\circ} \mathrm{C} 、 750{ }^{\circ} \mathrm{C} 、 800{ }^{\circ} \mathrm{C} 、 850{ }^{\circ} \mathrm{C}$ and $900{ }^{\circ} \mathrm{C}$ ) at the rate of $30^{\circ} \mathrm{C} / \mathrm{min}$ by a high temperature furnace (type KSL-1100X-L). When the heating process was over, we kept samples at designed temperature for 30 minutes in order to ensure samples heated evenly, and then let them to cool naturally.

The longitudinal wave velocity of samples was measured by RSM-SY5 Wave Detector whose emission voltage is $500 \mathrm{~V}$. Ultrasonic pulse method was used, and sampling interval was $0.5 \mu$ s. The Brazilian test was carried out in our test by a computer-controlled hydraulic universal testing machine (type WES-D1000) which collects the load, time and displacement data automatically. The load at a rate of $0.3 \mathrm{kN} / \mathrm{s}$ was measured by an oil pressure sensor and meanwhile a cylindrical capacitor displacement sensor was used to measure the displacement of sandstone samples. The experimental process was performed by the control program which using the data interface with 
system. In order to obtain more accurate results, the repetitive test was performed 4 times at each temperature and the test values with large discreteness were removed. The average values of tensile strength and longitudinal wave velocity of sandstone samples after different temperatures treated were shown in Tab.1.

\section{Test results and analysis}

\section{1 variation of tensile strength}

The tensile strength $\sigma_{t}$ (MPa) based on Brazilian test is calculated by the formula (1) [28].

$$
\sigma_{t}=\frac{2 P}{\pi D t}
$$

Where $P$ is the peak load, $\mathrm{N} ; D$ is the diameter of the disc, mm and $t$ is the thickness of the disc, $\mathrm{mm}$.

The tensile strength of sandstone samples changes significantly along with the temperature (shown in Fig.2). From $25^{\circ} \mathrm{C}$ to $300{ }^{\circ} \mathrm{C}$, the average value of tensile strength decreases a little from 5.69 $\mathrm{MPa}$ to $4.62 \mathrm{MPa}$. At the range of $300{ }^{\circ} \mathrm{C}$ to $600{ }^{\circ} \mathrm{C}$, the average value of tensile strength decreases with a magnitude of 53.14 percent from $4.62 \mathrm{MPa}$ to $2.38 \mathrm{MPa}$. From $600{ }^{\circ} \mathrm{C}$ to $800{ }^{\circ} \mathrm{C}$, the average value of tensile strength is just a slight downtrend from $2.38 \mathrm{MPa}$ to $2.21 \mathrm{MPa}$. In the last phase (from $800{ }^{\circ} \mathrm{C}$ to $900{ }^{\circ} \mathrm{C}$ ), the average value of tensile strength decreases sharply about 75.32 percent from 2.21 MPa to 0.55 MPa.

\subsection{Relationship between tensile strength and longitudinal wave velocity}

The sound wave can spread in rocks due to the elastic properties. The propagation velocity is influenced by mineral composition, degree of consolidation, porosity, and so on [15]. When rocks subjected to high temperature, internal defects and macro-cracks will grow. The increase of cracks and porosity lead to the decrease of tensile strength and longitudinal wave velocity. For the same material, the relationship between tensile strength and longitudinal wave velocity can be written as 
[8]:

$$
\sigma_{t}=a\left(\mathrm{~V}_{p}+c\right)^{2}
$$

Where $\mathrm{V}_{p}$ is longitudinal wave velocity; $a, c$ are the constant.

The results of longitudinal wave velocity and tensile strength are given in Fig.3. The variations of tensile strength and longitudinal wave velocity versus temperature are similar and can be divided into four phases: room temperature to $300^{\circ} \mathrm{C}, 300^{\circ} \mathrm{C}$ to $600^{\circ} \mathrm{C}, 600^{\circ} \mathrm{C}$ to $800^{\circ} \mathrm{C}, 800^{\circ} \mathrm{C}$ to $900^{\circ} \mathrm{C}$. A quadratic fitting curve of tensile strength and longitudinal wave velocity is fitted with the red curve in Fig.4, and can be expressed in mathematics as Eq.(3):

$$
\sigma_{t}=1.597-1.772 \mathrm{~V}_{p}+0.858 \mathrm{~V}_{p}^{2}, \quad \mathrm{R}^{2}=0.770
$$

The correlation coefficient of the curve is 0.770 , suggesting that the data are fitted well.

\subsection{Relationship between tensile strength and total energy absorbed per unit thickness of disc}

Load-displacement curves (shown in Fig.5) of Brazilian disc under different temperatures generally experiences the process of compaction, linear evolution and decline after peak point. The yield step before peak stress is not obvious, showing that the sandstone samples are in a strong brittle failure state. The disc specimens of sandstone lost bearing capacity in a short time after the axial load reaching the peak value. With the increase of axial load, micro-cracks will appear and connect to forming the macro-fissures. Sandstone samples were damaged after axial load reaching the peak value (shown in Fig.6). The appearance and development of cracks are the macroscopic expression of thermodynamics, which reflects the accumulation and transformation of energy consumption [16]. During the loading process, uniformly distributed load exerted by universal testing machine does work at the disc specimens, which can be entirely transformed into the total absorbed energy of the disc ignoring the external heat dissipation. The load and axial displacement are $P_{i}$ and $\Delta l_{i}$ respectively when the disc specimens are loaded to the step $i$. The total energy absorbed per unit thickness of disc $(K)$ is expressed as [16]: 


$$
K=\int P_{i} \Delta l_{i} / t
$$

When the total displacement is equal to the limit displacement (displacement corresponding to the peak load), total energy absorbed per unit thickness of disc also reaches the maximum $K_{0}$ which decreases gradually with the increase of temperature (shown in Fig.7). A linear curve of $\sigma_{t}-K_{0}$ is fitted with the red curve in Fig.8, and can be expressed with an equation:

$$
\sigma_{t}=0.282+48.683 K_{0}, \mathbf{R}^{2}=0.950
$$

The correlation coefficient of the curve is 0.950 , suggesting that the data are fitted very well. Therefore, the variations of tensile strength and total energy absorbed per unit thickness of disc along with the temperature are consistent.

\section{Discussions}

There are many factors (i.e. porosity, filling medium of pore, water content) that mainly depend on the mineral composition and structure characteristics affecting the physical and mechanical properties of rocks. The sandstone is a heterogeneous body with different minerals which have different thermal expansion coefficient at high temperature, forming the thermal stress [1]. The maximum value of thermal stress often occurs at the junction of mineral particles. The connection of interface between the mineral particles is broken if the thermal stress reaches or exceeds the ultimate strength. Therefore, the micro-fissures would extend and develop, and it would be partially retained even if the sandstone samples are cooled down to room temperature. At the same time, it is known that the absorbed water would escape around $100{ }^{\circ} \mathrm{C}$; the bounded water escape between $100{ }^{\circ} \mathrm{C}$ and $300{ }^{\circ} \mathrm{C}$; crystal water would escape below $400{ }^{\circ} \mathrm{C}$; and structural water of mineral would escape above $300{ }^{\circ} \mathrm{C}[12,15,29]$. With the increase of temperature, the decomposition of minerals in rocks also leads to an increase in internal structural defects. The physical and mechanical properties of sandstone change in different degrees by those factors above. 
Tensile strength, longitudinal wave velocity and total energy absorbed per unit thickness of disc with temperature may be divided into four phases.

(1) $25-300{ }^{\circ} \mathrm{C}$. In this phase, the quality of sandstone decreases a little bit (as shown in Fig.9) due to the escape of free and combined water. The voids in sandstone would increase simultaneously, which could accommodate the deformation caused by the expansion of mineral grains. Therefore, the tensile strength, longitudinal wave velocity and total energy absorbed per unit thickness of disc are just a slight downtrend.

(2) $300-600{ }^{\circ} \mathrm{C}$. In this phase, structural water and crystal water in minerals evaporate, such as dehydroxylation of kaolinite at approximately $541{ }^{\circ} \mathrm{C}$ [30,31]. At the same time, the most conspicuous effect of the thermal stress between mineral particles is the expansion of quartz, leading to new cracks. The volume expansion rate of quartz is nearly linear before $300{ }^{\circ} \mathrm{C}$, but presents an exponential growth from $300{ }^{\circ} \mathrm{C}$ to $600{ }^{\circ} \mathrm{C}$ (as shown in Fig.10). Specifically, quartz has a phase transformation at approximately $573{ }^{\circ} \mathrm{C}$ (from $\alpha$ phase to $\beta$ phase) which makes the volume of quartz increase sharply. The micro-fissures would develop and extend, and it would be partially retained though beta quartz would return to alpha quartz when cooled down to room temperature. Therefore, the tensile strength, longitudinal wave velocity and total energy absorbed per unit thickness of disc decrease rapidly.

(3) $600-800{ }^{\circ} \mathrm{C}$. In this phase, many minerals would melt [32] and metallic bonding would fracture (such as Ca-O, K-O, Na-O, and Al-O) [33]. Meanwhile, the decomposition of dolomite and generation of $\mathrm{CO}_{2}$ increase the porosity [31] and reduce the quality of sandstone rapidly (as shown in Fig.9). Therefore, the tensile strength, longitudinal wave velocity and total energy absorbed per unit thickness of disc continue to decrease.

(4) $800-900{ }^{\circ} \mathrm{C}$. In this phase, the thermal stress continues to increase. Quartz has a phase 
transformation from $\beta$ phase to $\beta$-tridymite phase at approximately $870{ }^{\circ} \mathrm{C}$, which makes the volume of quartz increase by $16 \%$. At the same time, a large amount of micro-fissures increase and connect to forming the macro-fissures (as shown in Fig.11), which makes mineral particles on the surface and the edge of cracks of specimens fall off. The quality of sandstone decreases rapidly (as shown in Fig.9). Therefore, the tensile strength, longitudinal wave velocity and total energy absorbed per unit thickness of disc decrease sharply. Zhang et al. [34-35] had also confirmed the acute reduction of rock strength after $800{ }^{\circ} \mathrm{C}$.

Zhao et al. [8] and Liu et al. [27] had also studied the variation of rock's tensile strength versus temperature (as shown in Fig.12). Compared to our test results, their research presented important similarities. Especially in the first two phases, tensile strength decreased a little from room temperature to $300{ }^{\circ} \mathrm{C}$ and decreased rapidly from $300{ }^{\circ} \mathrm{C}$ to $600{ }^{\circ} \mathrm{C}$. Generally speaking, when sandstone subjected to high temperature, these factors (i.e. loss of water, decomposition of minerals and thermal stress) would work together and make internal defects grow, contributing to the decrease of tensile strength.

\section{Conclusion}

In order to study how the tensile strength of sandstone varies after high temperature, Brazilian test was conducted, with the focus of such study of its variation with temperature as longitudinal wave velocity, total energy absorbed per unit thickness of disc and mass loss rate. The following conclusions can be drawn:

(1) Temperature has a significant impact on the tensile strength of sandstone, which is related to the loss of water and minerals and the effect of thermal stress. The changing trends of tensile strength, longitudinal wave velocity and total energy absorbed per unit thickness of disc are similar.

(2) The variation of tensile strength with temperature can be divided into four phases: from room 
temperature to $300{ }^{\circ} \mathrm{C}, 300-600{ }^{\circ} \mathrm{C}, 600-800{ }^{\circ} \mathrm{C}, 800-900{ }^{\circ} \mathrm{C}$. The first phase corresponds to the escape of free and combined water. Between $300{ }^{\circ} \mathrm{C}$ and $600{ }^{\circ} \mathrm{C}$, the most conspicuous effect of the thermal stress is the expansion of quartz, contributing to the rapid decrease of tensile strength. The melt of minerals, decomposition of dolomite and fracture of metallic bonding are demonstrated as the sustained reduction of tensile strength from $600-800{ }^{\circ} \mathrm{C}$. Finally, tensile strength decreases sharply due to the formation of macro-fissures above $800{ }^{\circ} \mathrm{C}$.

\section{Acknowledgments}

This research was supported by the National Science Foundation of China (Grant No. 41672279) and the Priority Academic Program Development of Jiangsu Higher Education Institutions. Sun Qiang also acknowledges the support of the China Scholarship Council (CSC, Grant No. 201506425041) travel grant and the support of the Department of Civil and Environmental Engineering at the University of North Carolina at Charlotte.

\section{References}

[1] P. Wang, J.Y. Xu, S. Liu, T.F. Cheng, Research on Dynamic mechanical properties of sandstone at high temperature, Acta Armamentarii. 34 (2) (2013) 203-208.

[2] Q. Sun, W. Zhang, L. Xue, Z. Zhang, T. Su, Thermal damage pattern and thresholds of granite, Environ. Earth. Sci. 74 (3) (2015) 2341-2349.

[3] P.K. Gautam, A.K. Verma, M.K. Jha, K. Sarkar, T.N. Singh, R.K. Bajpai, Study of Strain Rate and Thermal Damage of Dholpur Sandstone at Elevated Temperature, Rock. Mech. Rock. Eng. (2016). doi:10.1007/s00603-016-0965-5.

[4] G. Wu, A.G. Xing, L. Zhang, Mechanical characteristics of sandstone after high temperatures, Chin. J. Rock. Mech. Eng. 26 (10) (2007) 2110-2116.

[5] P.G. Ranjith, R.V. Daniel, B.J. Chen, M.S.A. Pereea, Transformation plasticity and the effect of temperature on the mechanical behavior of Hawkesbury sandstone at atmospheric pressure, Eng. Geol. 151 (2012) 120-127. 
[6] Y.P. Zarichnyak, A.E. Ramazanova, S.N. Emirov, Contribution of thermal radiation in measurements of thermal conductivity of sandstone, Phys. Solid. State. 55 (12) (2013) 2436-2441.

[7] P.K. Gautam, A.K. Verma, S. Maheshwar, T.N. Singh, Thermomechanical Analysis of Different Types of Sandstone at Elevated Temperature, Rock. Mech. Rock. Eng. 49 (2016) 1985-1993.

[8] H.B. Zhao, G.Z. Yin, X.S. Li, Experimental study of characteristics of tensile burned gritstone, Rock. Soil. mech. 31 (4) (2010) 1143-1146.

[9] H. Mónika, Changes in sandstones of historical monuments exposed to fire or high temperature, Fire. Tech. 38 (2002) 373-382.

[10] S.J. Du, H. Liu, H.T. Zhi, H.H. Chen, Testing study on mechanical properties of post-high-temperature granite, Chin. J. Rock. Mech. Eng. 23 (14) (2004) 2359-2364.

[11] Z. Wu, B.D. Qin, L.J. Chen, Y.J. Luo, Experimental study on mechanical character of sandstone the upper plank of coal bed under high temperature, Chin. J. Rock. Mech. Eng. 24 (11) (2005) 1863-1867.

[12] Q. Sun, C. Lü, L. Cao, W. Li, J. Geng, W. Zhang, Thermal properties of sandstone after treatment at high temperature, Int. J. Rock. Mech. Min. Sci. 85 (2016) 60-66.

[13] E. Santoyo, A. GarcíA, J.M. Morales, E. Contreras, G. Espinosa-Paredes, Effective thermal conductivity of Mexican geothermal cementing systems in the temperature range from $28^{\circ} \mathrm{C}$ to $200^{\circ} \mathrm{C}$, Appl. Therm. Eng. 21 (17) (2001) 1799-1812.

[14] J. Geng, Q. Sun, W. Zhang, C. Lü, Effect of high temperature on mechanical and acoustic emission properties of calcareous-aggregate concrete, Appl. Therm. Eng. 106 (2016) 1200-1208. [15] W.Q. Zhang, Q. Sun, S.Q. Hao, J.S. Geng, Experimental study on the variation of physical and mechanical properties of rock after high temperature treatment, Appl. Therm. Eng. 98 (2016) 1297-1304.

[16] H.J. Su, H.W. Jing, H.H. Zhao, Q. Yin, Study on tensile strength and size effect of red sandstone after high temperature treatment, Chin. J. Rock. Mech. Eng. 34 (S1) (2015) 2879-2887.

[17] Y. Zong, L. Han, T. Qu, S. Yang, Mechanical properties and failure characteristics of fractured 
sandstone with grouting and anchorage, Int. J. Min. Sci. Technol. 24 (2) (2014) 165-170.

[18] Z. Zhang, F. Gao, Experimental investigation on the energy evolution of dry and water-saturated red sandstones, Int. J. Min. Sci. Technol. 25 (3) (2015) 383-388.

[19] F.E. Heuze, High-temperature mechanical, physical and thermal properties of granitic rocks-a review, Int. J. Rock. Mech. Min. Sci. Geo. Mech. Abstr. 20 (1) (1983) 3-10.

[20] B. Singh, P.G. Ranjith, D. Chandrasekharam, D. Viete, H.K. Singh, Thermo-mechanical properties of Bundelkhand granite near Jhansi, India, Geomech. Geophys. Geo-energ. Geo-resour. 1 (1-2) (2015) 35-53.

[21] D.Q. Dan, H. Konietzky, M. Herbst, Brazilian tensile strength tests on some anisotropic rocks, Int. J. Rock. Mech. Min. Sci. 58 (2013) 1-7.

[22] G. Hondros, The evaluation of Poisson's ratio and the modulus of materials of a low tensile resistance by the Brazilian (indirect tensile) test with particular reference to concrete, Aust. J. Appl. Sci. 10 (1959) 243-268.

[23] Q.Z. Wang, X.M. Jia, S.Q. Kou, Z.X. Zhang, P.A. Lindqvist, The flattened Brazilian disc specimen used for testing elastic modulus, tensile strength and fracture toughness of brittle rocks: analytical and numerical results, Int. J. Rock Mech. Min. Sci. 41 (2) (2004) 245-253.

[24] A. Coviello, R. Lagioia, R. Nova, On the measurement of the tensile strength of soft rocks, Rock. Mech. Rock. Eng. 38 (4) (2005) 251-273.

[25] S. Wisetsaen, C. Walsri, K. Fuenkajorn, Effects of loading rate and temperature on tensile strength and deformation of rock salt, Int. J. Rock. Mech. Min. Sci. 73 (2015) 10-14.

[26] D.Q. Dan, H. Konietzky, Numerical simulations and interpretations of Brazilian tensile tests on transversely isotropic rocks, Int. J. Rock. Mech. Min. Sci. 71(4) (2014) 53-63.

[27] S. Liu, J. Xu, Mechanical properties of Qinling biotite granite after high temperature treatment, Int. J. Rock. Mech. Min. Sci. 71 (2014) 188-193.

[28] ASTM, Standard test method for splitting tensile strength of intact rock core specimens. ASTM Standards on Disc, 04.08. Desination:D3967; 2001. 
[29] Q. Sun, Z.Z. Zhang, L. Xue, S.Y. Zhu, High temperature phase transformation and physical and mechanical properties of rock, Chin. J. Rock. Mech. Eng. 32 (5) (2013) 935-942.

[30] J.Z. Kuang, T.S. Qiu, F. Shi, Effect of heat treatment on structure transformation and activities of kaolinite, Chin. J. Nonferrous. Metals. 22 (1) (2012) 258-264.

[31] E. Plevová, L. Vaculíková, A. Kožušníková, T. Daněk, M. Pleva, M. Ritz, G.S. Martynová, Thermal study of sandstones from different Czech localities, J. Therm. Anal. Calor. 103 (2011) 835-843.

[32] Y. Qin, N.X. Tian, Y. Zhang, J. Han, Experimental study on physical properties of post-high-temperature diorite, Chin. J. Geotech. Eng. 37 (7) (2015) 1226-1231.

[33] P. Zhao, W.H. Xie, X.S. Wang, F. Gao, The real time experimental research on rock's SEM under high temperature, Mech. Eng. 28 (3) (2006) 64-67.

[34] Z.Z. Zhang, F. Gao, X.L. Xu, Experimental study of temperature effect of mechanical properties of granite, Rock. Soil. Mech. 32 (8) (2011) 2346-2352.

[35] X.L. Xu, F. Gao, X.M. Shen, C.H. Jin, Research on mechanical characteristics and micropore structure of granite under high-temperature, Rock. Soil. Mech. 31 (6) (2010) 1752-1758. 


\section{Figure captions}

Fig.1 Test flow

Fig.2 Variation of tensile strength after different temperatures treated

Fig.3 Variations of tensile strength and longitudinal wave velocity after different temperatures treated

Fig.4 The quadratic fitting curve of tensile strength and longitudinal wave velocity

Fig.5 Load-displacement curves of Brazilian disc

Fig.6 The damage of Brazilian disc

Fig.7 Variations of tensile strength and total energy absorbed per unit thickness of disc $\left(K_{0}\right)$ after different temperatures treated

Fig.8 The linear curve of tensile strength and total energy absorbed per unit thickness of disc $\left(K_{0}\right)$

Fig.9 Variations of tensile strength, longitudinal wave velocity, total energy absorbed per unit thickness of disc and mass loss rate after different temperatures treated

(a) Variations of tensile strength and mass loss rate after different temperatures treated

(b) Variations of longitudinal wave velocity, total energy absorbed per unit thickness of disc and mass loss rate after different temperatures treated

Fig.10 Variations of tensile strength tensile strength, longitudinal wave velocity, total energy absorbed per unit thickness of disc and volume expansion after different temperatures treated

(a) Variations of tensile strength and volume expansion after different temperatures treated

(b) Variations of longitudinal wave velocity, total energy absorbed per unit thickness of disc and volume expansion after different temperatures treated

Fig.11 Sandstone samples at $900{ }^{\circ} \mathrm{C}$

Fig.12 Variations of tensile strength versus temperature 
Fig.1 Test flow

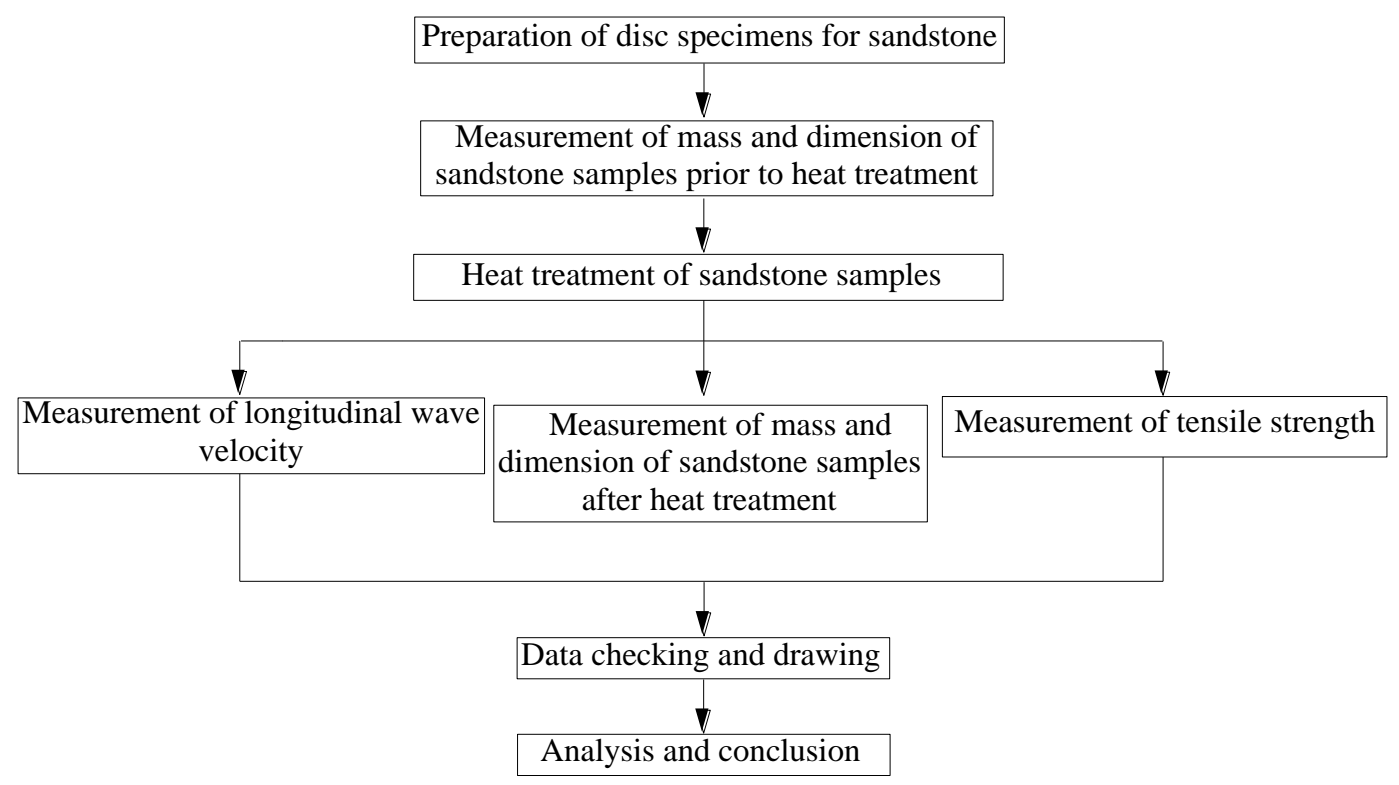


Fig.2 Variation of tensile strength after different temperatures treated

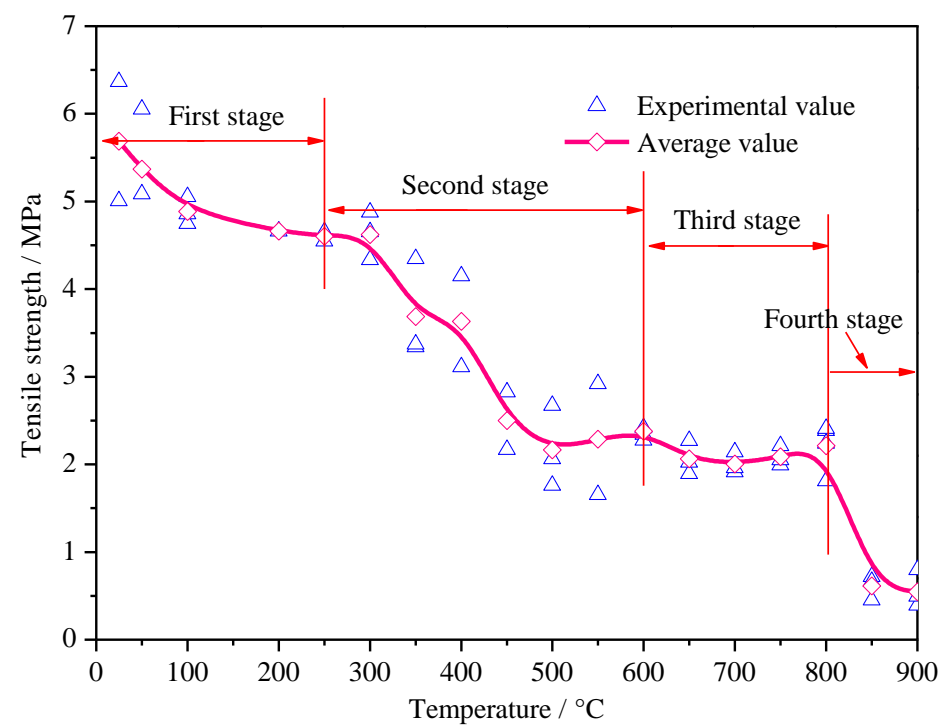


Fig.3 Variations of tensile strength and longitudinal wave velocity after different temperatures treated

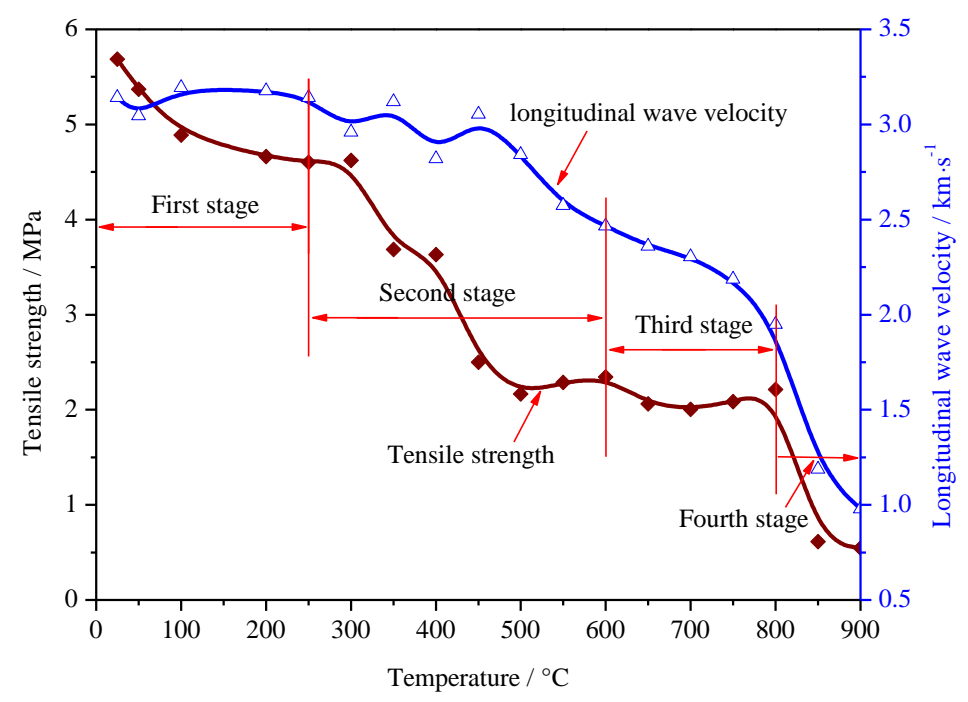


Fig.4 The quadratic fitting curve of tensile strength and longitudinal wave velocity

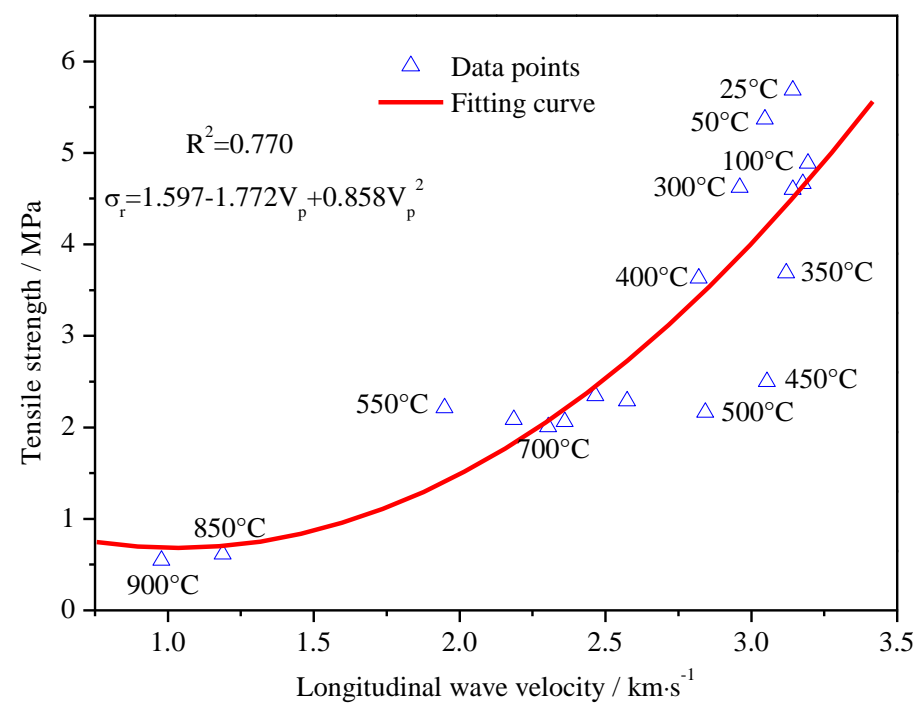


Fig.5 Load-displacement curves of Brazilian disc

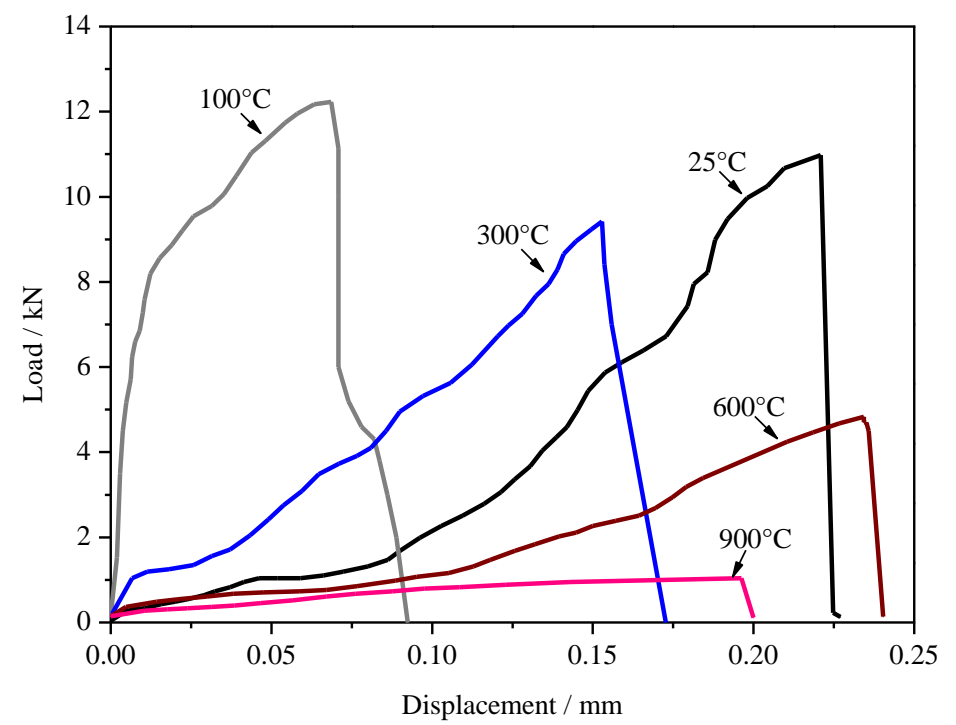


Fig.6 The damage of Brazilian disc

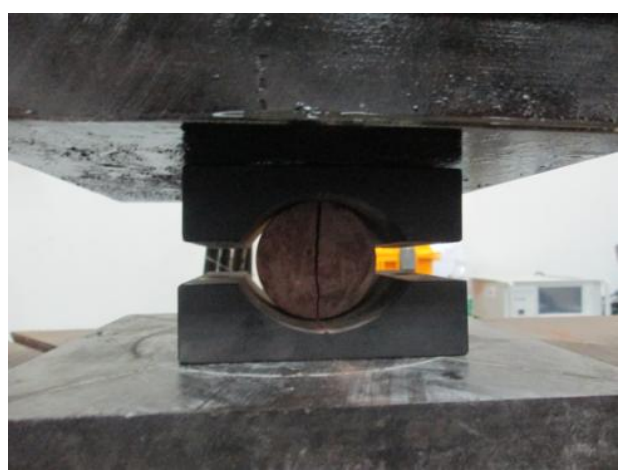


Fig.7 Variations of tensile strength and total energy absorbed per unit thickness of disc $\left(K_{0}\right)$ after different temperatures treated

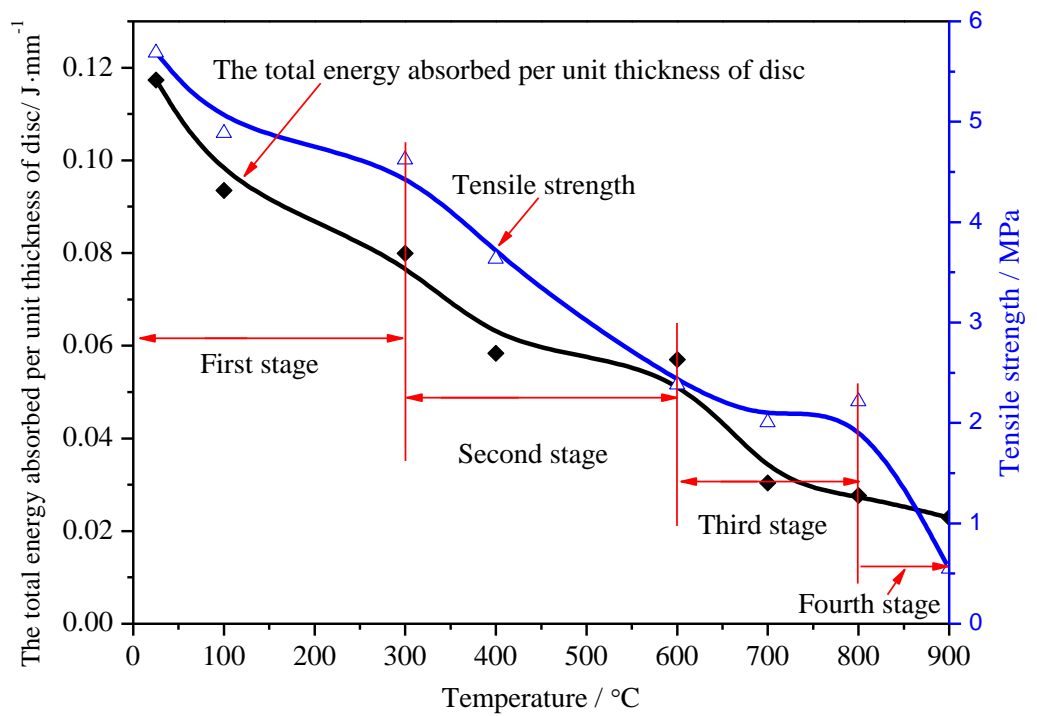


Fig.8 The linear curve of tensile strength and total energy absorbed per unit thickness of disc $\left(K_{0}\right)$.

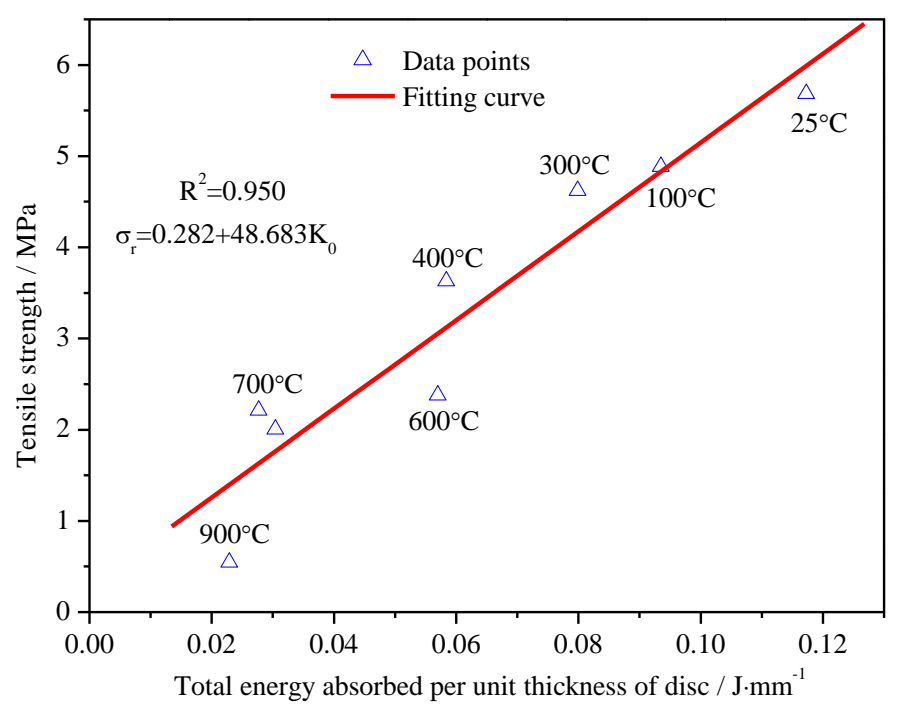


Fig.9 Variations of tensile strength, longitudinal wave velocity, total energy absorbed per unit thickness of disc and mass loss rate after different temperatures treated

(c) Variations of tensile strength and mass loss rate after different temperatures treated

(d) Variations of longitudinal wave velocity, total energy absorbed per unit thickness of disc and mass loss rate after different temperatures treated

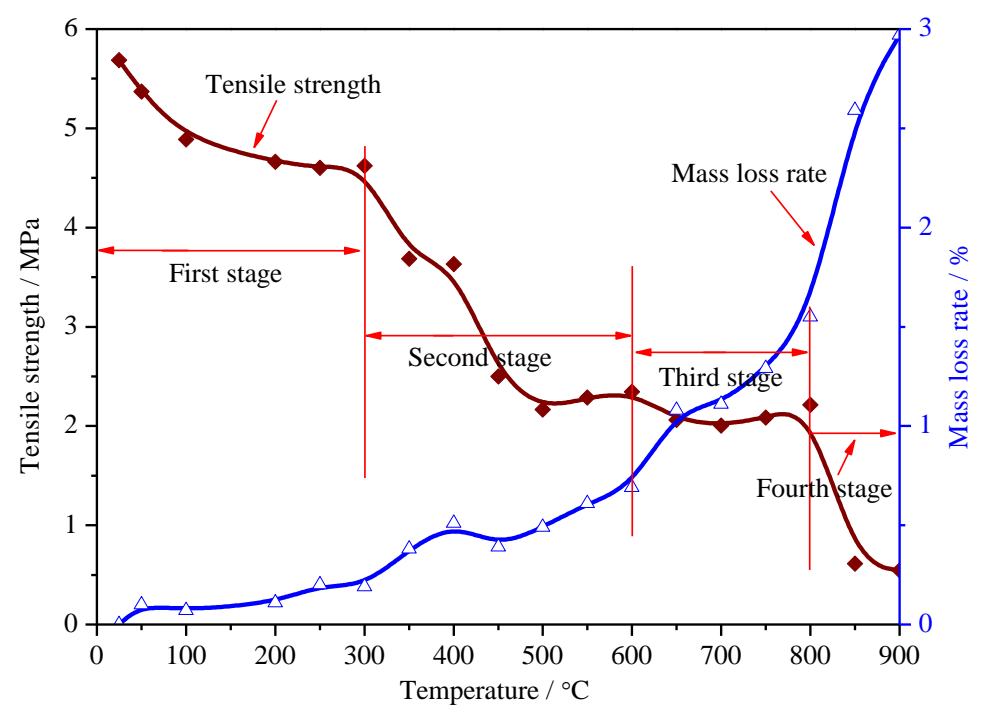

(a) 


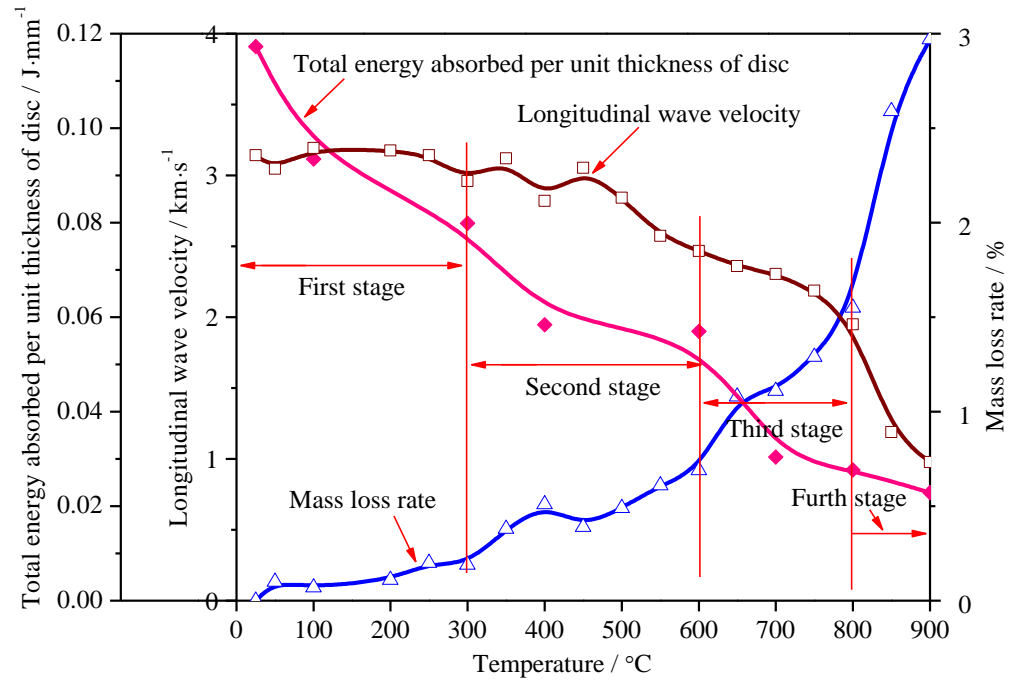

(b) 
Fig.10 Variations of tensile strength tensile strength, longitudinal wave velocity, total energy absorbed per unit thickness of disc and volume expansion after different temperatures treated

(c) Variations of tensile strength and volume expansion after different temperatures treated

(d) Variations of longitudinal wave velocity, total energy absorbed per unit thickness of disc and volume expansion after different temperatures treated

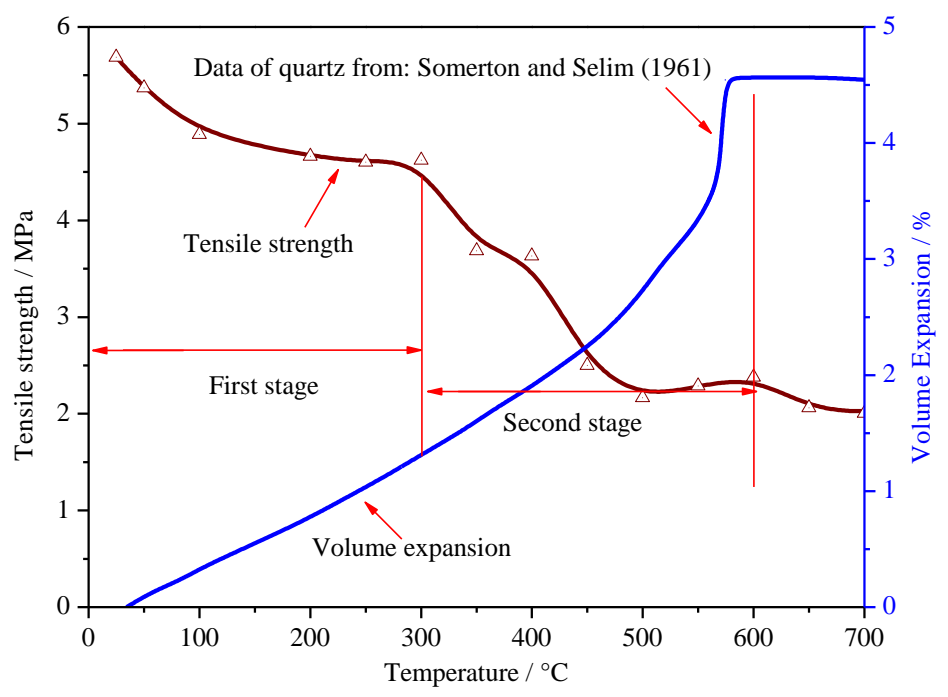

(a) 


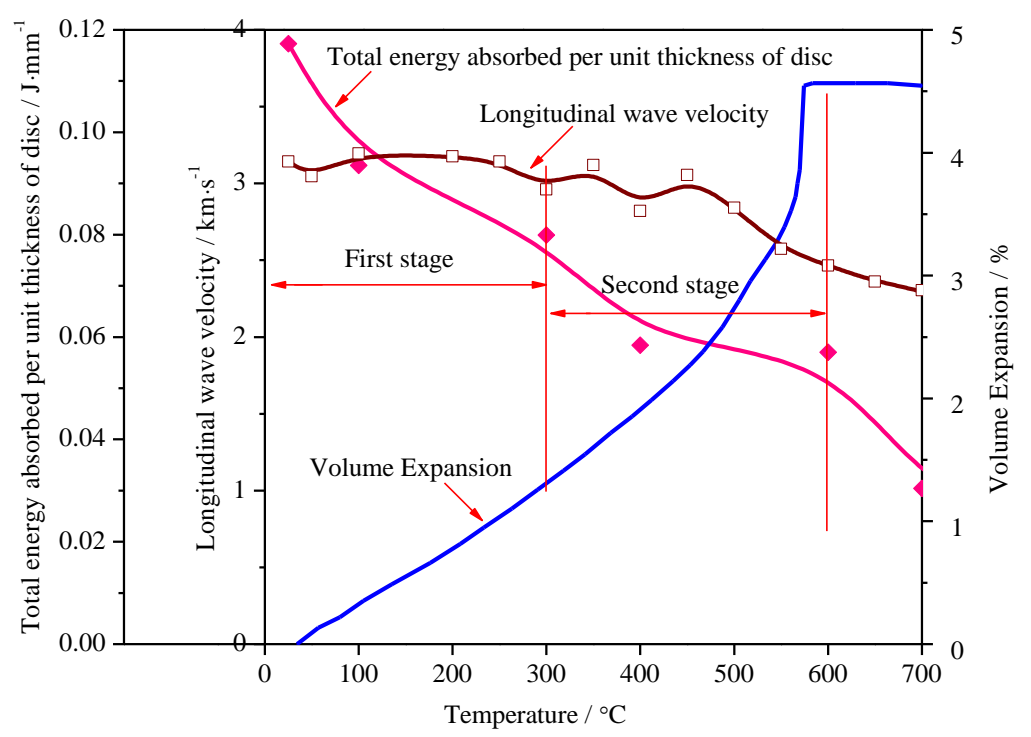

(b) 
Fig.11 Sandstone samples at $900{ }^{\circ} \mathrm{C}$

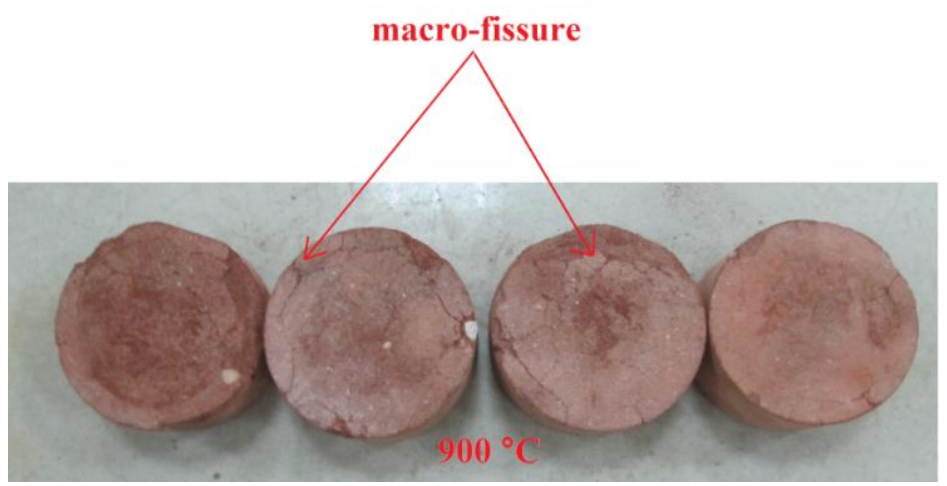


Fig.12 Variations of tensile strength versus temperature

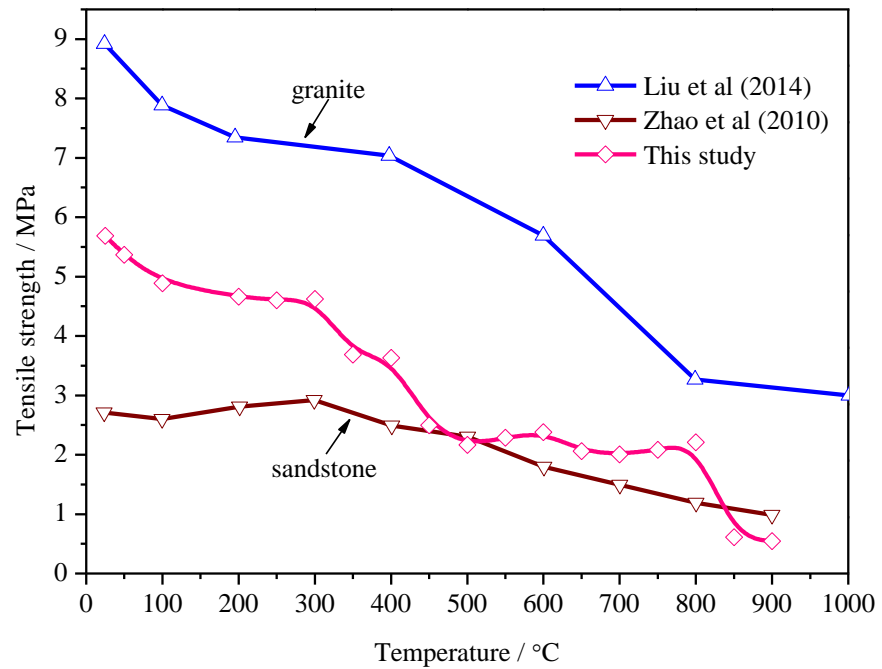


Tab.1 The average values of tensile strength and longitudinal wave velocity of sandstone samples after different temperatures treated

\begin{tabular}{ccc}
\hline Temperature $/{ }^{\circ} \mathrm{C}$ & Tensile strength/Mpa & Longitudinal wave velocity $/ \mathrm{km} \cdot \mathrm{s}^{-1}$ \\
\hline 25 & 5.69 & 3.14 \\
50 & 5.37 & 3.05 \\
100 & 4.89 & 3.19 \\
200 & 4.66 & 3.18 \\
250 & 4.60 & 3.14 \\
300 & 4.62 & 2.96 \\
350 & 3.69 & 3.12 \\
400 & 3.63 & 2.82 \\
450 & 2.50 & 3.05 \\
500 & 2.17 & 2.84 \\
550 & 2.29 & 2.57 \\
600 & 2.38 & 2.47 \\
650 & 2.06 & 2.36 \\
700 & 2.00 & 2.30 \\
750 & 2.09 & 2.19 \\
800 & 2.21 & 1.95 \\
850 & 0.61 & 1.19 \\
900 & 0.55 & 0.98 \\
\hline
\end{tabular}

